\title{
Interprofessional Informatics Education: A Digital Health Game
}

\author{
Leanne M CURRIE ${ }^{\mathrm{a}, 1}$, Victoria WOOD ${ }^{\mathrm{b}}$, Joseph ANTHONY ${ }^{\mathrm{b}}$ and John CHENG $^{\mathrm{c}}$ \\ ${ }^{a}$ School of Nursing, University of British Columbia-Vancouver, BC, Canada \\ ${ }^{\mathrm{b}}$ Faculty of Medicine, University of British Columbia-Vancouver, BC, Canada \\ ${ }^{\mathrm{c}}$ Centre for Teaching, Learning and Technology, University of British Columbia- \\ Vancouver, BC, Canada
}

\begin{abstract}
The purpose of this project was to develop and implement an interprofessional informatics curriculum. We developed a digital health serious game at the centre of this curriculum where the focus was a team-based approach to learning technologies used in the healthcare setting. The overall satisfaction scores were moderately high after the game. Serious games can be engaging for health sciences students.
\end{abstract}

Keywords. Informatics education, serious game, interprofessional education

\section{Introduction}

Healthcare professionals from all disciplines need to be supported to develop new knowledge and skills to work effectively in a healthcare environment where information and communication technology (ICT) is playing an increasingly prominent role. However, the nature of ICT necessitates an approach to learning that moves beyond the acquisition of knowledge about existing and emerging technologies, and toward an approach that focuses on using ICT in a way that supports the care of individual patients [1]. This project involved the development of a Health Informatics curriculum designed to give interprofessional groups of health professional students a grounding in the principles of safe, effective, person-centred care within the context of ICT use. There is growing use of serious games for healthcare education [2], thus we developed a serious game at the core of the curriculum.

\section{Methods}

An innovative, technology-enhanced game that students play in interprofessional teams is at the heart of our Health Informatics Curriculum. The game was iteratively designed and tested with multiple student and faculty groups before being delivered to over 500 students from eight professions. The curriculum involves an online preparatory module orienting students to the strengths, limitations, and current Canadian context of ICT. The second part of the curriculum is the technology-enhanced game. During the game,

\footnotetext{
${ }^{1}$ Corresponding Author, Leanne M Currie, RN, PhD, University of British Columbia, School of Nursing, Vancouver, BC, V5T 2B5, Canada; E-mail: Leanne.currie@ubc.ca.
} 
students competed against other interprofessional teams to earn the most points by considering the most appropriate use of ICT for a particular patient within a particular context of care. Collaboratively, groups made decisions about what technology to use and how to use the technology, taking into consideration limitations of the technology or infrastructure, the patients' digital literacy and patients' access to ICT. The focus of the game was not on clinical care but on the effective use of ICT across the healthcare team.

\section{Results}

Preliminary findings indicated that the use of a game makes students' learning experience "fun", which they suggest makes the content more memorable. According to students, learning was also enhanced by the way in which the game facilitated the normalized integration of a transgender patient, where their gender identity was not the focus of the case; and introduced them to innovative models of primary and community care being implemented in Canada. Integrating a young patient with whom the students could relate, who was marginally poor and with limited digital literacy and access to ICT, facilitated conversations about the most appropriate use of ICT. As a result of this innovative, technology-enhanced game, students feel able to: analyze how ICT supports or inhibits safe, collaborative, person-centred care; identify and propose strategies that support the use of ICT in a manner that enhances (i.e. does not interfere with) the relationship between patients/clients and their healthcare team; and look for opportunities to use ICT to support patient safety and quality improvement.

\section{Conclusions}

The way in which this technology-enhanced game has been developed allows for other patient cases and contexts of care to be integrated as a way to foster different interprofessional discussions about the appropriate use of ICT.

\section{References}

[1] Skiba DJ, Barton AJ, Knapfel S, Moore G, Trinkley K. Infusing informatics into interprofessional education: The iTEAM (Interprofessional Technology Enhanced Advanced practice Model) project. Studies In Health Technology And Informatics 201 (2014), 55-62.

[2] Haoran G, Bazakidi E, Zary N. Serious games in health professions education: Review of trends and learning efficacy. Yearbook Of Medical Informatics 28 (2019), 240-248. 